\title{
Re: The pathophysiology of stress urinary incontinence: a systematic review and meta-analysis. Int Urogynecol J 32, 501-552 (2021)
}

\author{
Peter Emanuel Petros ${ }^{1,2}$ (D) \\ Received: 4 May 2021 / Accepted: 24 May 2021 / Published online: 6 July 2021 \\ (C) The International Urogynecological Association 2021
}

\section{Dear Editors}

\section{A damaged pubourethral ligament is the prime cause of SUI}

In an extensive review covering some 50 journal pages [1], the authors proposed several possible pathogeneses for the causation of stress urinary incontinence (SUI), but concluded that "standardized approaches to measurement are needed to generate higher levels of evidence."

The authors seemingly ignored the original works confirming the role of a damaged pubourethral ligament (PUL) in the pathogenesis of SUI [2] and also, the inspirational anatomical works of Robert Zacharin [3]. Other important discoveries in 1990 [2] were how three opposite reflex muscle forces act around a competent PUL to close the urethra; that the pathogenesis of SUI was a weak PUL extending on effort to invalidate urethral closure forces to cause SUI [2]; and finally, the means to correct such a weakness in animal experiments showing how an implanted tape produces new collagen to reinforce the damaged ligaments. The primacy of PUL pathogenesis can be directly proven by placing a hemostat immediately behind the symphysis at the origin of the PUL to mechanically support it and control loss of urine on coughing (https://youtu.be/0UZuJtajCQU).

The same test monitored by transperineal ultrasound control [4] demonstrates the anatomical basis of this test. On straining, the urethra was opened out at the bladder neck and distally. On applying the hemostat as shown in the video to mechanically support the PUL at the middle of the urethra,

Peter Emanuel Petros

pp@kvinno.com

1 University of Western Australia School of Mechanical and Mathematical Engineering, Perth, WA, Australia

2 Elizabeth Bay, Australia closure is seen to occur immediately at both the distal urethra and the bladder neck.

The final proof of a damaged PUL as the main pathogenic factor for SUI is the midurethral sling, 10,000,000 operations to date, which mechanically supports the PUL by creation of a collagenous neoligament [2], at the same time restoring urethral closure geometry exactly as per the ultrasound [4], which is surely sufficient to satisfy the authors' closing issue [1]: "standardized approaches to measurement are needed to generate higher levels of evidence."

\section{Declarations}

Conflicts of interest None.

\section{References}

1. Falah-Hassani K, Reeves J, Shiri R, et al. The pathophysiology of stress urinary incontinence: a systematic review and meta-analysis. Int Urogynecol J. 2021;32:501-52. https://doi.org/10.1007/s00192020-04622-9.

2. Petros PE, Ulmsten U. An integral theory of female urinary incontinence. Acta Obstet Gynecol Scand Suppl. 1990;153:69:7-31.

3. Zacharin RF. A suspensory mechanism of the female urethra. J Anat. 1963;97:423-7.

4. Petros PE, Von Konsky B. Anchoring the midurethra restores bladder neck anatomy and continence. Lancet. 1999;354(9193):997-8.

Publisher's note Springer Nature remains neutral with regard to jurisdictional claims in published maps and institutional affiliations. 